\title{
Nietzsche - "La Naissance de la Philosophie" - 1938*
}

\author{
Euryalo Cannabrava**
}

\begin{abstract}
Resumo: Refletindo sobre uma recente tradução francesa de um trabalho de juventude de Nietzsche, o autor mostra que o filósofo alemão não estaria preocupado em fazer uma análise lógica minuciosa dos textos dos pensadores pré-socráticos, em articular seus fragmentos numa síntese harmoniosa e tampouco em oferecer uma interpretação original de suas ideias. Para ele, a singularidade de Nietzsche, que tinha uma aptidão única para transpor os temas da metafísica, da moral e da cultura ao plano da subjetividade lírica, seria a de mostrar a admirável aventura dos primeiros pensadores gregos que, emergindo de um mundo caótico, lendário e mitológico, entregaram-se à tarefa de reconstruir a realidade dentro das linhas luminosas da razão.
\end{abstract}

Palavras-chave: Nietzsche - filosofia - pré-socráticos racionalidade - interpretação.

A tradução francesa de um dos primeiros trabalhos de Nietzsche sobre a origem da Filosofia e da arte trágica na Grécia oferece oportunidade para o debate de alguns temas significativos e atuais.

É curioso que o interesse pela obra do pensador alemão tenha aumentado à medida que se desfaziam certas lendas e ideias falsas sobre o valor de sua personalidade, o sentido de sua obra e a solidez

* Publicado no Diário de Pernambuco. Pernambuco, Domingo, 14 de Maio de 1939, p. 8. (Arquivo DP/D.A. Press, em 28/07/2016).

** Euryalo Cannabrava (1906-1981). Filósofo brasileiro. Autor de Seis temas do espírito moderno (1941) e Teoria da decisão filosófica (1977). 
Cannabrava, E.

de sua cultura filológica. Verifica-se com o autor de "Assim falava Zaratustra" o contrário do que, geralmente, acontece às grandes figuras da história, da arte e do pensamento, pois estas perdem muito do seu prestigio à proporção que nelas se descobrem imperfeições e lacunas, ao passo que esse estranho filósofo parece crescer aos nossos olhos em virtude dos próprios erros e dos próprios defeitos.

O que há de realmente extraordinário em Nietzsche não é, como se acreditou durante muito tempo, a profundidade da análise psicológica, a força original da dialética subjetiva, o poder incomparável da imaginação ou a sutileza do raciocínio crítico. Nenhuma dessas qualidades revela o traço original e especifico desse pensador desabusado cuja incapacidade para a criação de um sistema, a reconstituição meticulosa dos textos antigos e a crítica aos valores permanentes da construção científica não diminui a profundidade e o fulgor da sua obra especulativa. A mensagem desse filósofo, que era sem dúvida um esteta, não nos interessa mais pelas reivindicações violentas, pelo tom vulcânico das objurgatórias e das terríveis blasfêmias, mas, sobretudo, pela aptidão inigualável de Frederico Nietzsche para transpor os temas da metafísica, da moral e da cultura ao plano subjetivo da sensibilidade lírica. O lirismo era a forma natural e espontânea do seu gênio inquieto e da sua fantasia turbulenta.

É claro que as teorias do super-homem, da vontade de poder, da supremacia dos valores vitais e do sentido estético da existência não se apoiam em dados objetivos, em demonstrações convincentes ou provas racionais, mas somente numa exaltação lírica do sentimento que transforma a realidade em símbolos e imagens, que participa plenamente da embriaguez da criação e que a entrega, de corpo e alma, aos motivos heroicos e trágicos como se neles se encerrasse o segredo do nosso destino.

A filosofia de Nietzsche não se reduz a axiomas e postulados frios, não reveste nunca as formas abstratas do raciocínio algébrico 
e está longe de se confundir com os enunciados inteiriços da lógica e das formas inalteráveis da teoria do conhecimento. Há uma página do seu livro "Aurora" que descreve a arte do filólogo como uma espécie de ourivesaria em que a delicadeza do tato, o trabalho sutil e apurado, o sentido alerta da combinação de cores e nuances sobrelevam a quaisquer outras qualidades necessárias para a prática do oficio. É evidente que o filósofo deve ter qualquer coisa do filólogo e do ourives, embora a obra de Nietzsche lembre, algumas vezes, a empresa fabulosa dos ciclopes ou a tarefa a que se entregou Hércules nas cavalariças de Augias.

Havia em Nietzsche uma aversão profunda pelas formas objetivas do conhecimento, pelos conceitos impessoais da verdade pura, pelos esquemas rígidos de um cientificismo ingênuo e falsamente lógico. Ele aspirava, constantemente, atingir as regiões em que a alegria de viver se expande sem receio e a força do lirismo dionisíaco se liberta dos preconceitos absurdos, das crenças religiosas e das convenções morais. $O$ sentido último de toda a sua obra é colocar a vida acima das verdades eternas, e forjar uma nova hierarquia dos valores em que a necessidade de saber seja postergada pelo ímpeto claro dos instintos e pelas afirmações irreprimíveis da vontade de poder. A filosofia, segundo o conceito nietzschiano, seria apenas a maneira consciente e intensa de satisfazer as tendências vitais, a expressão lírica dos impulsos primários e o prolongamento natural de uma atividade que se confunde com as funções fisiológicas e com as fundamentais reações do ser que se adapta ao ambiente externo. $\mathrm{O}$ filósofo nada mais consegue refletir do que sua visão de mundo que está ligada a estrutura vital, às condições do próprio temperamento e à forma específica dos servos. Não há nenhuma dialética que se emancipe do fundo biológico que a tornou possível, assim como não se admite a existência de uma teoria do conhecimento ou de uma logística inteiramente alheia ao ritmo das funções fisiológicas e as peculiaridades constitucionais de seus criadores. 
Cannabrava, E.

É por isso que as figuras dos grandes pensadores gregos do período pré-socrático só interessam a Nietzsche como personalidades singulares, reformadores pan-helênicos, verdadeiros super-homens, que procuraram substituir o culto dos mitos pela reflexão critica sobre a natureza, a cosmologia e o problema do ser. Ninguém poderá atribuir ainda, ao filósofo alemão, qualidades excepcionais na interpretação filológica dos textos, pois o que mais nos espanta é o desembaraço com que Nietzsche inventa, fantasia e adultera o sentido da hermenêutica antiga, substituindo o método clássico pelo capricho das suas opiniões pessoais e pela intuição muitas vezes arbitrária de sua sensibilidade de esteta.

Esse ensaio sobre a filosofia grega vale mais como um poema em prosa do que como um trabalho de erudição. Representa muito mais a própria personalidade do autor do que a personalidade dos filósofos pré-socráticos. Traduz muito melhor as ideias de Nietzsche do que as opiniões de Tales, de Empédocles ou de Anaxágoras. Tratase positivamente de um intérprete infiel, pouco sereno, incapaz de trasladar o texto para uma língua moderna, sem alterar-lhe a essência e incutir-lhe um sentido novo, original e arbitrário. Não há paralelo possível entre o ensaio de Nietzsche e os trabalhos mais recentes de Diels, John Burnet e Ernst Howald. Mas o que falta ao filósofo da vida em matéria de método, disciplina e fidedignidade, sobra-lhe em riqueza de sugestões, de pontos de vista e de comentários estéticos.

Assistimos através de suas páginas vibrantes, ao nascimento da especulação, isto é, ao tateio de um raciocínio crítico que ousa inquirir as causas primárias que esboça, com força viril, os lineamentos de uma cosmologia e que interroga, corajosamente, o mistério do ser. Vamos encontrar entre os pré-socráticos a origem dos sistemas idealistas, materialistas, dualistas e pluralistas, a fonte da metafisica mais elevada e as formas rudimentares do pensamento científico ocidental. Os pré-socráticos foram os iniciadores de uma ontologia e de uma teoria do conhecimento, lançaram as bases da concepção 
mecânica do real e prepararam o terreno para a dialética idealista, o eudemonismo ético e a interpretação teleológica do universo.

Os críticos modernos mostram-se bastante céticos em relação à pretendida filiação espiritual desses pensadores às culturas préhelênicas da Índia, do Egito e da China. Ninguém repetiria mais a tentativa de Rachet para descobrir diretas conexões entre Heráclito e Zaratustra, entre eleatas e a doutrina védica do Atman, entre os pitagóricos e os chineses, entre a doutrina de Anaxágoras e o monoteísmo judaico. Caminha-se, cada vez mais, para reconhecer na filosofia pré-socrática o traço autêntico da originalidade, atribuindo-se a esses pensadores gregos o incomparável privilégio de ter iniciado a cultura ocidental. Mas o que interessa, sobretudo, acentuar, é a tonalidade especifica de cada um desses sistemas, é o matiz particular de cada uma dessas doutrinas, é a expressão pessoal e inconfundível de cada uma dessas teorias.

Existe entre Tales de Mileto e Heráclito uma diferença muito mais profunda do que entre Platão e Aristóteles ou do que entre Hegel e Kant. Não se pode aproximar as concepções de um Demócrito da dialética de um Parmênides ou do hermetismo matemático de um Pitágoras. Apesar de só restarem fragmentos de toda a obra présocrática, percebe-se que entre Empédocles, Anaximandro e Zenon não existe, apenas, a diferença das posições doutrinárias, mas o vinco profundo de personalidades inteiramente diversas e, sobretudo, a expressão de possibilidades de vida que não se confundem.

Nietzsche admira, acima de tudo, nos pensadores antigos, que viveram no século das guerras médicas, a sua maravilhosa experiência, essa libertação progressiva da influência constante dos mitos, das lendas órficas e das cosmogonias primitivas, e essa afirmação, através de individualidades autônomas, de um pensamento que se emancipa pouco a pouco do invólucro denso das crenças religiosas. $\mathrm{O}$ historiador surpreende nesses filósofos anteriores a Sócrates a essência do gênio helênico, isto é, a condensação de todas as qualidades e aptidões 
Cannabrava, E.

que asseguram aos gregos posição excepcional no curso da história. Trata-se de toda uma cultura, do principio e fim de uma civilização, de uma fase da filosofia que se pode considerar perfeita e acabada.

$\mathrm{O}$ ensaio de Nietzsche não pode figurar entre as monografias eruditas que os alemães publicam, periodicamente, sobre os principais representantes do pensamento grego. $\mathrm{O}$ autor de "Humano, demasiado Humano" não se deixa reduzir pela investigação minuciosa dos textos, não procura articular os fragmentos em uma síntese harmoniosa do pensamento pré-socrático e não oferece nenhuma interpretação original das ideias dos filósofos gregos. O que Frederico Nietzsche pretendeu descrever foi a admirável aventura desse grupo de homens, que emergiam de um mundo caótico, lendário e mitológico para se entregar à tarefa de reconstruir a realidade dentro das linhas puras luminosas da razão.

Nota-se perfeitamente que esses sábios se concentram no esforço de ordenar as coisas dispersas, de hierarquizar os valores, de subordinar o universo às leis do pensamento. Percebe-se a luta a que eles se entregam para traduzir em uma linguagem pura o reflexo da atividade ordenadora do espirito e o desenvolvimento progressivo dos conceitos da razão. A sabedoria antiga, conjunto de noções e reconhecimentos anteriores à formação das ciências particulares, apresentava-se assim bastante diferenciada nos diversos sistemas, mas constituem, na sua fase final, uma síntese histórica, um complexo harmonioso de normas e princípios e uma aventura comum do espírito na tentativa de interpretar o universo.

Após muitos séculos de dispersão e de variedade infinita de concepções, quando o homem se sente fatigado de tantas doutrinas, sistemas-teorias, é bastante compreensível que se admire a serenidade desses primeiros filósofos que legislavam sobre o curso dos fenômenos naturais com a segurança dos magos, dos hierofantes e dos profetas. É bem possível que a proliferação atual das construções metafísicas e das teorias filosóficas não nos permita compreender o pensamento 
grego na época da arte trágica, pois o que nos parece hoje descolorido, amorfo e inconsistente exigia uma energia intelectual e um esforço cognitivo incomparavelmente mais intenso do que o esforço e a energia necessária para a criação da técnica e dos instrumentos da civilização mecânica.

A separação do mito, da metafísica popular, dos símbolos cosmogônicos e das fáceis explicações antropomórficas para atingir em cheio a substância das coisas naturais e formular os princípios eternos de qualquer investigação das causas primárias exige uma força intelectual e um gênio especulativo muito mais admiráveis do que o sentido pragmático, a habilidade técnica e o talento científico que tornaram possíveis a invenção do aeroplano, do telefone, do rádio e da máquina de contar. É por isso (como verificaremos em crônica posterior) que não se poderá nunca refutar a sabedoria desses antigos filósofos com os argumentos fáceis que o progresso das ciências particulares e o desenvolvimento do mundo civilizado põem à disposição de qualquer espírito superficial e incapaz de admirar a verdadeira grandeza.

\begin{abstract}
Reflecting on a recent French translation of a youthful work from Nietzsche, the author shows that the German philosopher would not be concerned in doing a logically detailed analysis of Pre-socratics texts, in articulating their fragments in an harmonious summary, neither in offering an original interpretation of their ideas. From his point of view, Nietzsche's uniqueness - and Nietzsche had an unique expertise in transposing metaphysical, moral e cultural themes to the level of lyrical subjectivity - would be in presenting the magnificent adventure of the first Greek thinkers who, arising from a chaotic, fabled and mythological world, devoted themselves to the task of reconstruction of reality along the lighting lines of reason.
\end{abstract}

Key-words: Nietzsche - philosophy - pre-socratics - rationality - interpretation. 